\title{
Como tem se dado a atuação do assistente social nas empresas privadas?
}

\section{Resumo}

O presente artigo tem como objetivo apresentar como vem se dando a atuação do assistente social nas empresas privadas. O estudo foi realizado por meio de uma pesquisa qualitativa, mediante entrevistas com profissionais da área, através de roteiro semi-estruturado, em seis empresas privadas. Como principais resultados observou-se que a atuação do assistente social nas empresas privadas é marcada por diversos antagonismos, no entanto, acredita-se ser possível direcionar seu trabalho para os interesses dos trabalhadores em paralelo aos interesses de lucratividade do capital, realizando-os por meio de estratégias articuladas ao projeto ético-político do Serviço Social.

Palavras-chave: Serviço Social, atuação profissional, empresa privada.

\section{How has been taking the role of the social worker in private companies?}

\begin{abstract}
This article aims to present how has been taking the role of the social worker in private companies. The study was conducted through a qualitative research through interviews with professionals, through semi-structured script in six private companies. As main results, it was observed that the role of the social worker in private companies is marked by many contradictions, however, it is believed to be possible to direct their work for the interests of workers in parallel to the profitability of capital interests, making them through strategies articulated the ethical-political project of Social Work.
\end{abstract}

Key-words: Social service, professional activity, private company.

(1) Pós-Graduanda em Gestão Estratégica de Pessoas Universidade Federal de Juiz de Fora (Stephanialacerda@hotmail.com)

(2) Professora da Universidade Federal de Juiz de Fora (UFJF) - Campus avançado de Governador Valadares. Também é professora do MBA em Gestão de Pessoas da UFJF. (debora1@powermail.com.br)

(3) Professor Adjunto da Faculdade de Administração e Ciências Contábeis da Universidade Federal de Juiz de Fora, onde exerce os cargos de Vice Coordenador do Mestrado Acadêmico em Administração e Vice Chefe do Departamento de Ciências Administrativas. (victorclaudio@uol.com.br) 


\section{Introdução}

A atuação do assistente social nas empresas privadas remonta a meados dos anos 1940, proveniente da luta dos operários por melhores condições de trabalho, visto que passaram a se reconhecer enquanto classe trabalhadora com necessidades em comum. O trabalho do assistente social nas empresas privadas desde aquela época tem como intuito minimizar a contradição entre empresa e trabalhador (capital x trabalho).

Gomes et al (2010) explicam que as organizações privadas passaram por diversas mudanças e, a partir de 1970, em virtude do processo de reestruturação produtiva, o que acarretou na crise de acumulação capitalista e consequentemente na demanda por novas formas de gestão da força de trabalho.

Segundo Mota (2010), a justificativa para as empresas privadas demandarem assistentes sociais em seu quadro de funcionários é pela importância dada à manutenção da qualidade da força de trabalho dos trabalhadores, que pode ser afetada por comportamentos divergentes, falta de motivação, necessidades materiais, dependência química, problemas de saúde dentre outros.

Nesse sentido, o profissional é requisitado a atuar junto à gestão de benefícios para suprir a carência material, como também com caráter educativo, por meio de orientações relativas aos direitos do cidadão e através de programas e projetos sociais.

Cesar (2010) relata que o assistente social é reconhecido pelo seu trabalho de integração junto ao trabalhador, sendo requisitado para atender as necessidades humanas, auxiliando na construção da sociabilidade, o que acarretará em um comportamento produtivo de acordo com os preceitos das organizações. Dessa forma, o Serviço Social é considerado pelas empresas como mecanismo de promoção de um melhor desempenho dos trabalhadores.

Ainda de acordo com a autora, o assistente social possui também atividades voltadas às orientações quanto a direitos e serviços sociais, por meio da concessão de benefícios, encaminhamentos a rede sócio assistencial, análise socioeconômica, além das novas atividades relativas à otimização e racionalização de recursos, inclusão das avaliações de desempenho e trabalho com a comunidade.

Dourado (2010) relata ainda que o Serviço Social é uma profissão que, devido à sua singularidade, apresenta uma aptidão para construir uma visão abrangente acerca do processo de trabalho por meio da sua inserção junto aos trabalhadores.

O artigo tem por objetivo apresentar como vem se direcionando a atuação dos assistentes sociais nas empresas privadas, tendo como finalidade, conhecer como são desenvolvidas as atividades desse profissional no espaço sócio-ocupacional relatado. Realizando-a por meio de uma pesquisa, com roteiro semi-estruturado em seis empresas privadas de pequeno, médio e grande porte.

O intuito do estudo não é constatar conceitos de quais são as competências do assistente social nas empresas privadas, mas sim obter subsídios para um maior acúmulo teórico e tecer algumas reflexões sobre esse processo de trabalho para assim, poder contribuir ao estudo do Serviço Social.

O artigo está estruturado em sete seções, contando com esta introdução. A próxima destaca conceitos de gestão por competência, bem como o processo histórico da construção desse pensamento. A seção subsequente trará a evolução histórica do Serviço Social no espaço sócio-ocupacional das empresas privadas. Já a quarta seção se refere às competências do assistente social nas organizações privadas. A seção posterior relatará acerca da metodologia utilizada na pesquisa realizada. E a sexta e sétima seções, respectivamente, trarão como foco de estudo, os resultados obtidos em campo e as considerações finais desse estudo. 


\section{Conceito de Competência}

Segundo Ferreira e Lana (2007), o conceito de competência é utilizado na área de administração desde as primeiras teorias organizacionais, contudo seu significado era distinto do que temos atualmente. Nesse artigo, não se pretende retomar todas as correntes teóricas, visto que esse tema já vem sendo tratado por muitos autores, entretanto, considera-se válido ressaltar o seu desenvolvimento histórico.

Deve ser destacado o início do século XX, com o advento do taylorismo, momento em que o conceito de competência foi englobado à linguagem organizacional, passando a ser utilizado para predicamentar um indivíduo que possua habilidades eficazes para desempenhar um determinado papel na organização, conforme explicitam Carbone et al (2006).

A partir de 1970, com a expansão da competição e o crescimento das organizações, uma nova forma de se apreender a competência foi se moldando. De acordo com Ferreira e Lana (2007), foi retirado o âmago da capacidade, passando-o para o desempenho, ou melhor, tratando não apenas dos comportamentos do indivíduo, mas também das realizações por ele conquistadas.

Segundo Silva (2005), na metade da década de 1990, o conceito de competência ganha um status estratégico, conforme proposto por estudiosos como Prahalad e Hamel, em seus artigos e livros. Como consequência, as empresas passam a criar projetos relacionados ao tema, com o intuito de identificar conhecimentos e atitudes necessários para agregar valor ao negócio.

Ainda segundo Silva (2005), no Brasil, o conceito de competência começa a ser discutido no início dos anos 1990, com destaque para grupos de estudos na área de RH promovidos na Universidade de São Paulo (USP). Outro marco importante citado pelo autor ocorreu em 1995, nas empresas DuPont e Copesul, que destacaram-se nacionalmente pelos seus programas de remuneração baseados em competências e habilidades.

De acordo com Brandão e Guimarães (2001), a constância na utilização do termo competência na gestão organizacional fez com que o mesmo obtivesse diversos significados. Contudo, é possível verificar a existência de duas correntes conceituais, consoante ao que apresenta Dutra (2001). A primeira trata a competência como sendo um conjunto de qualificações que habilita a pessoa a exercer determinado trabalho. Esta concepção foi apresentada por autores norte-americanos, tais como Boyatzis, 1982 e McClelland, 1973. A outra se refere à competência como conjunto das realizações desenvolvidas pela pessoa, aquilo que ela produz no trabalho.

Nesse diapasão, Carbone et al (2006) passaram a definir competência como sendo combinações de conhecimentos, habilidades e atitudes, expressas pelo desempenho profissional, que agregam valor a pessoa e a organização.

Sob essa perspectiva, pode-se considerar que um dos conceitos mais completos para competência, conforme explicita Silva (2005), seria proveniente da junção dos conceitos de dois estudiosos sobre o tema:

a competência de uma pessoa pode ser compreendida como sua capacidade de entrega. A competência é inseparável da ação e os conhecimentos teóricos ou técnicos devem ser utilizados de acordo com a capacidade de se executar as decisões que a ação sugere. Uma pessoa é competente quando amplia a sua capacidade de entrega e agrega valor ao negócio, à empresa onde atua, a ele próprio e ao meio em que vive. Competência é a capacidade de uma pessoa gerar resultados e atender a objetivos pessoais e/ou organizacionais (SILVA, 2005, p. 11). 
Fleury e Fleury (2001, p.3), por sua vez, tratam a competência como "um saber agir responsável e reconhecido, que implica mobilizar, integrar, transferir conhecimentos, recursos e habilidades, que agreguem valor econômico à organização e valor social ao indivíduo".

De acordo com Tadeucci et al (2012), gestão por competência é um princípio gerencial que possui a finalidade de estimular os trabalhadores para que busquem a ampliação de seus conhecimentos e habilidades, com o objetivo de alcançar um melhor desempenho profissional. Esse processo se faz por meio da identificação de competências essenciais e de habilidades necessárias, para se desempenhar, da melhor maneira possível, uma função na organização. Com o intento de possuir um quadro de funcionários mais talentosos e produtivos, o que, por conseguinte, propiciará uma maior produtividade, comprometimento, participação e maior motivação para o exercício de suas funções.

Brandão e Babry (2005) relatam que a gestão por competência vem sendo considerada como modelo gerencial alternativo aos instrumentos tradicionalmente utilizados pelas empresas, tendo como intenção gerenciar o gap de competências, para assim restringir ao máximo a disparidade entre as competências já disponíveis, com as que são indispensáveis para a conclusão dos objetivos da organização.

Leme (2005) afirma que a gestão por competência, é uma ferramenta que visa auxiliar as empresas a compreender que elas precisam treinar os trabalhadores para que alcancem o objetivo proposto.

Uma definição interessante é a proposta por Carbone et al (2006), para quem competências são conjuntos sinergéticos de conhecimentos, habilidades e atitudes que credenciam um indivíduo a exercer uma dada função. Ferreira (2012) relata também que alguns autores entendem competências como sendo um conjunto de realizações adquiridas pelo indivíduo em seu trabalho.

Em síntese, competências profissionais podem ser entendidas como a capacidade demonstrada pelos trabalhadores de gerar resultados, de desempenhar de modo adequado suas tarefas. Tal conceito pode, também, auxiliar na compreensão da capacidade desempenhada por um indivíduo ou uma categoria profissional.

A seção seguinte aborda a evolução histórica do Serviço Social, no que concerne a sua atuação nas empresas privadas.

\section{A Evolução Histórica do Serviço Social no Espaço Sócio-Ocupacio- nal das Empresas}

O Serviço Social na área empresarial tem seu início em 1941 por meio das empresas públicas, e nas privadas em meados de 1943, segundo lamamoto e Carvalho (1982), sendo este livro um dos clássicos no conjunto das obras dessa profissão. Tal surgimento ocorre em virtude da cena política da época, através do movimento dos operários por melhores condições de trabalho. O objetivo da contratação desse profissional é com o propósito de minimizar os conflitos existentes oriundos da contradição capital x trabalho.

A atuação dos assistentes sociais nas empresas se intensificou na década de 1970, dado que as relações empresariais demandavam a ação desse profissional, a fim de que respondessem ás necessidades da reprodução material da força de trabalho.

Gomes et al (2010), relatam que o processo de reestruturação produtiva vem acarretando diversas mudanças no desenvolvimento das organizações privadas, desde a década de 1970. A crise de acumulação capitalista requisitou novas orientações, determinando um novo processo da gestão da força de trabalho. A partir dos anos 1980, surgem novas tecnologias e consequentemente mudanças no mundo do trabalho. Nesse contexto, as empresas começam 
a desenvolver projetos voltados para o envolvimento dos trabalhadores com os interesses da organização. Com isso, o trabalho do assistente social passa por diversas alterações para com essas novas requisições.

Os autores citados salientam ainda que o assistente social passa a vir a ser requisitado a tratar dos problemas relativos à produtividade, prestação de serviços sociais, assessoramento as chefias, assim como o trabalho de cunho assistencial e educativo para com os trabalhadores e seus familiares.

Mota (1985), uma das autoras de referência no que concerne a atuação dos assistentes sociais em empresas, afirma que a presença desses profissionais nas organizações privadas vem atestar que a expansão capitalista gera a criação de novas necessidades sociais, ou seja, o assistente social vem contribuir na área empresarial no que concerne a área assistencial e educativa. A contribuição desses profissionais pode ocorrer por meio de trabalhos individuais ou coletivos junto aos trabalhadores, podendo contemplar ainda atendimentos aos familiares.

A inserção de assistentes sociais no ambiente empresarial vincula-se à importância atribuída à qualidade dos trabalhos desempenhados pelos funcionários, dado que eles podem ser afetados por carências materiais e psicológicas, ideias/comportamentos divergentes aos pregados pela organização, dentre outros. Uma correta assistência social pode também ajudar a evitar ações trabalhistas.

De acordo com Amaral e Cesar (2009), em meados da década de 1980 é possível observar a presença de assistentes sociais em empresas, o que foi favorecido pela conjuntura brasileira da época. Visto que, a classe trabalhadora começa a se organizar politicamente, através da criação de partidos, sindicatos, etc.

Nos anos 1990, conforme proposto por Cesar (2010), o Serviço Social, na área de Recursos Humanos, passou por algumas mudanças no que se refere à racionalidade técnica e ideopolítica, que refuncionalizam o tradicional em prol do moderno e mesclam, no campo das atividades profissionais velhas e novas demandas. Com isso, é requerido dos profissionais a adoção de estratégias que afirmem a legitimidade social.

É na virada do milênio, segundo Amaral e Cesar (2009), que ocorrem mudanças significativas na área empresarial, período esse definido por alguns autores como sendo a fase da "acumulação flexível". As características desse período repercutiram diretamente na lógica do funcionamento das empresas, assim como no trabalho do assistente social.

Nesse sentido, o profissional de Serviço Social, passou a interagir diretamente com os trabalhadores com o propósito de tornar menos drástico possível o processo de transição, que se deu através da introdução de tecnologias de ponta, diferentes modalidades de contratação, flexibilização do trabalho, entre outros.

A atuação do assistente social também passou por um processo de requalificação, posto que novas exigências vêm ao encontro desse profissional. Um dos seus papéis é assegurar a aderência e o comprometimento dos trabalhadores para com as novas formas de trabalho. Esse processo de adesão dos trabalhadores as novas requisições de suas funções, foram viabilizadas, muitas vezes, por meio de programas de recursos humanos voltados para o envolvimento com as metas, tais como: desenvolvimento de capacidades e habilidades; treinamento e desenvolvimento; remuneração pautada em resultados; gestão de benefícios e atuação na área de segurança do trabalho, voltado à prevenção de acidentes. Esta postura representa, de acordo com Amaral e Cesar (2009), a integração da Administração de Recursos Humanos com os princípios da Gestão da Qualidade Total.

Vale destacar que essas novas demandas são acrescidas às competências requeridas do profissional de Serviço Social. Além dessas, atribuições antigas ainda se encontram em voga, tais como a manutenção do caráter educativo, voltado para mudanças de hábitos e 
comportamentos, para que o trabalhador se adeque ao processo produtivo, assim como, relativo ao absenteísmo, alcoolismo, uso de drogas, afastamento do trabalho, conflitos familiares, dificuldades financeiras, dentre outros (MOTTA, 1985). Não se pode deixar de mencionar também a requisição no que concerne à mediação de conflitos entre a organização e funcionários.

Alguns programas de Gestão de Pessoas que esses profissionais costumam ser chamados a intervir são: Programas de Treinamento e Desenvolvimento, Programas Participativos (Gestão da Qualidade Total), Programa de Qualidade de Vida, Programa de Clima ou Ambiência Organizacional, dentre outros.

Os objetivos desses programas podem ser muito bem resumidos por Amaral e Cesar (2009), onde é relatado que a atuação do profissional de Serviço Social se dá por meio da mensuração dessas informações, as quais podem ser geradas, por exemplo, por meio da aplicação de entrevistas, com a finalidade de correlacionar as práticas de gestão com o clima organizacional da empresa. Tais resultados precisam ser analisados e transmitidos aos gestores, servindo como indicadores do que deve ser modificado na estrutura do processo de trabalho com vistas a aumentar a produtividade.

Amaral e Cesar (2009) relatam ainda que esses profissionais possuem um conjunto diverso de frentes de trabalho nas empresas, das quais destacaram: gestão de recursos humanos, programas participativos, desenvolvimentos de equipes, ambiência organizacional, ação comunitária, certificação social, educação ambiental, entre outros.

Dessa forma, pode-se perceber, segundo Cesar (2010), que o assistente social é requisitado para atuar na parte de assessoramento aos gestores das organizações, com a intenção de obter uma melhor administração das pessoas, gerando confiabilidade, aprendizado, crescimento e satisfação dos trabalhadores. Esse profissional é demandado para atuar na área de Gestão de Pessoas, com o interesse de dar respostas às necessidades humanas dos trabalhadores, contribuindo com a formação de um comportamento produtivo de acordo com as exigências da organização, sendo um fomentador da adesão do trabalho as novas formas de produção.

Ainda de acordo com Cesar (2010), o Serviço Social é requisitado para intervir nos problemas que afetam diretamente na produtividade do trabalhador, é aliada a intervenção de questões psicossociais, que não relacionam diretamente ao processo de trabalho, mas que vem a interferir diretamente no mesmo.

A seção subsequente aborda as competências que são apontadas como relevantes para os profissionais de Serviço Social atuantes nas empresas, conforme encontrado na literatura dessa área.

\section{As Competências do Assistente Social nas Organizações Privadas}

O Serviço Social nas organizações privadas se constitui como um espaço sócioocupacional em expansão nas últimas décadas, carecendo desse profissional um contínuo processo de elaboração de estratégias de atuação, em virtude da volatilidade das demandas apresentadas na área empresarial, assim como uma atualização constante.

Embora a inserção do assistente social no âmbito empresarial remonte a década de 1940, não possui uma legislação específica que trate da atuação desse profissional nas organizações privadas.

A Lei de Regulamentação da Profissão, Lei n8.662/1993, em seu Art. $4^{\circ}$ prevê como competências do assistente social: 
- elaborar, implementar, executar e avaliar políticas sociais junto a órgãos da administração pública, direta ou indireta, empresas, entidades e organizações populares;

- elaborar, coordenar, executar e avaliar planos, programas e projetos que sejam do âmbito de atuação do Serviço Social com participação da sociedade civil;

- encaminhar providências, e prestar orientação social a indivíduos, grupos e à população;

- orientar indivíduos e grupos de diferentes segmentos sociais no sentido de identificar recursos e de fazer uso dos mesmos no atendimento e na defesa de seus direitos;

planejar, organizar e administrar benefícios e Serviços Sociais;

- planejar, executar e avaliar pesquisas que possam contribuir para a análise da realidade social e para subsidiar ações profissionais;

- prestar assessoria e consultoria a órgãos da administração pública direta e indireta, empresas privadas e outras entidades;

prestar assessoria e apoio aos movimentos sociais em matéria relacionada às políticas sociais, no exercício e na defesa dos direitos civis, políticos e sociais da coletividade;

- planejamento, organização e administração de Serviços Sociais e de Unidade de Serviço Social;

- realizar estudos socioeconômicos com os usuários para fins de benefícios e serviços sociais junto a órgãos da administração pública direta e indireta, empresas privadas e outras entidades.

Conforme proposto por Cesar (2010), pode-se resumir o perfil comportamental exigido ao assistente social como sendo pautado em cinco requisitos básicos:

a) Conhecimento: significa ter um bom conhecimento das rotinas de trabalho de toda a empresa e de sua política, para assim ter subsídios necessários para responder as perguntas e dúvidas e resolver problemas.

b) Competência: faz-se necessário que o profissional tenha agilidade, organização e exatidão no desenvolvimento de suas atividades.

c) Atmosfera positiva: o profissional deve possuir um ambiente agradável para receber seu cliente, assim como deve-se ter uma comunicação clara e com fluência.

d) Cooperação: concerne na sua relação com a equipe, fazendo com que todos possuam subsídios para atingir suas metas e resultados, sempre com o propósito de melhorar a produtividade e a qualidade da produção.

e) Esforço extra: o profissional deve ser flexível, buscando fazer algo a mais, fornecendo alternativas e soluções para satisfazer as necessidades do cliente, mas também trazer algo de novo para surpreendê-lo.

Ainda segundo Cesar (2010), tais características revelam que a requalificação promovida pelas empresas, possui como objetivo a formação de um tipo particular de trabalhador. Aquele que além de estar capacitado para compreender, implementar e administrar novos padrões de 
organização, do processo de produção e dominar novas tecnologias, deva estar capacitado a assumir um comportamento produtivo que gere um desempenho estável e previsível. Desse modo, as principais habilidades exigidas aos assistentes sociais se encontram na flexibilidade e no dinamismo, obtendo assim, melhores resultados junto aos trabalhadores da organização.

Segundo Borralho et al (2011), o assistente social é dotado de competências que agregam valor ao processo de trabalho, visto que esse profissional é capaz de captar as singularidades do cotidiano de vida da força de trabalho. Fazendo isso por meio da sua criatividade, proposição das ações a serem desempenhadas, programas de melhoria do ambiente organizacional, qualidade de vida no trabalho, responsabilidade social; uma vez que é considerado agente propulsor da conscientização social na empresa.

De acordo com o que sugere Dourado (2010), o Serviço Social é uma profissão que de acordo com suas particularidades na divisão social e técnica do trabalho, apresenta aptidão em construir uma visão mais ampla acerca do processo de trabalho, com base em sua afinidade com os diferentes segmentos de trabalhadores.

\section{Metodologia}

O presente trabalho, quanto ao método de abordagem, realizou-se o dedutivo, posto que, o raciocínio partiu de estudos teórico-metodológicas, através de análise de referencial teórico e documental (geral) para avaliação das entrevistas com os profissionais da área (particular).

Já com relação a orientação a pesquisa é qualitativa, visto que tem por objetivo analisar os dados a partir da percepção dos entrevistados. A pesquisa de campo contou com uma entrevista com roteiro semi-estruturado, com o propósito de conhecer o processo de trabalho dos assistentes sociais nas organizações privadas.

No que concerne ao tipo de pesquisa, a mesma possui duas características: quanto aos fins e quanto aos meios. Quanto aos fins, segundo a divisão criada por Vergara (2011), foi de caráter exploratório, visto a pouca bibliografia sobre o tema e descritiva em virtude do grupo analisado, os assistentes sociais trabalhadores de empresas privadas. Já com relação aos meios, se deu através da pesquisa de campo, uma vez que foi utilizado levantamento de informações por intermédio da aplicação de entrevistas, e bibliográfico, onde foi realizada uma revisão da literatura, estudos de diversos conceitos e teorias sobre o tema abordado, utilizando-se documentos, livros, artigos científicos, revistas e trabalhos acadêmicos.

Vergara (2011), afirma que o universo é o agrupamento de elementos que apresentam as peculiaridades que serão o objeto a ser estudado. Definir o universo indica determinar que populações serão envolvidas, no caso desse estudo o universo esta compreendido na atuação do assistente social nas organizações privadas, o qual foram analisados oito profissionais de Serviço Social de seis empresas de diferentes ramos, tais como: prestação de serviços de saúde, mineração, logística, póstumos, de fornecimento de água e metalurgia.

No que se refere aos sujeitos foram entrevistados oito assistentes sociais atuantes nas organizações privadas, que para manter sigilo dos entrevistados, convencionou-se a nomenclatura de E1 a E8 para identifica-los. O critério utilizado para seleção dos entrevistados foi o banco de dados do Conselho Regional de Serviço Social (CRESS) e da faculdade de Serviço Social da Universidade Federal de Juiz de Fora (UFJF).

O levantamento de dados se deu por meio de entrevistas, que foram realizadas com aplicação de roteiro semi-estruturado, composto por dezesseis perguntas abertas e individuais. Os assistentes sociais foram previamente contatados por telefone onde foi realizada uma breve explicação acerca do propósito e objetivos da pesquisa, mencionando-se a voluntariedade de participar, o sigilo e consequentemente a marcação de um melhor horário para realização da entrevista. 
O tratamento dos dados foi realizado por meio da a análise de conteúdo, que segundo Bardin (2008), é um conjunto de técnicas de análise, com o objetivo de obter uma melhor descrição do conteúdo das mensagens, permitindo a conclusão dos conhecimentos proporcionados pela fala dos participantes, ou seja, o referencial teórico-metodológico nos permite um maior entendimento a respeito dos temas tratados no artigo, dando legitimidade as ações da autora.

Buscou-se com a análise dos dados levantados obter um conhecimento prático dos entrevistados acerca dos assuntos abordados para assim poder fazer uma análise crítica com embasamento conciso dos dados sobre o desenvolvimento do trabalho do profissional de Serviço Social nas organizações privadas.

Os dados foram obtidos mediante agrupamento das perguntas, o que orientou a análise das informações pontuadas pelos próprios profissionais entrevistados, visto que, as respostas foram reunidas em quatro categorias, criadas pela própria autora. Com o intuito de obter uma melhor análise do discurso, efetuando-se a leitura dos textos procurando amostras discursivas recorrentes, partilhadas pelos entrevistados.

Tomando por base que o tratamento dos dados envolve a categorização, ordenação, manipulação e sumarização desses, tendo em vista reduzir grandes quantidades de dados brutos a uma forma interpretável e mensurável, a autora optou por categorizar as questões agrupando-as de acordo com a tabela a seguir:

Tabela 1 - Categorização

\begin{tabular}{|c|c|c|}
\hline \multicolumn{2}{|c|}{ CATEGORIZAÇÃo } \\
\hline CATEGORIA 1 & Perfil Profis sional & Questão 1 \\
\hline CATEGORIA 2 & Processo de Formação & Ques tões 2, 3 e 4 \\
\hline CATEGORIA 3 & Atuação Profissional & Questões 5, 6, 7, 8, 9, 10 e 11 \\
\hline CATEGORIA 4 & $\begin{array}{c}\text { Facilitadores e Dificultadores do Processo } \\
\text { de Trabalho }\end{array}$ & Questões 12, 13, 14, 15 e 16 \\
\hline
\end{tabular}

Fonte: Elaborada pelos autores

No que diz respeito à limitação do método, destaca-se que os resultados obtidos representam a análise do discurso dos participantes, não correspondendo, necessariamente, à percepção dos demais assistentes sociais, uma vez que a entrevista foi realizada com oito profissionais. Dessa forma, considera-se relevante realizar a pesquisa com uma amostra maior de profissionais e em estados diferentes.

\section{Resultados Obtidos no Campo}

Para introduzir este item, vale ressaltar que foram entrevistados oito profissionais de Serviço Social em seis empresas privadas de diferentes ramos. Esse percentual de entrevistados, dentro do objetivo proposto, atende a perspectiva da pesquisa. No entanto, é importante destacar que o número de assistentes sociais atuantes nesse espaço sócioocupacional é significativamente maior. Dessa forma, não se pode tomar como unanimidade o relato dos mesmos, visto que o universo de profissionais é muito maior do que a amostra apresentada nesse estudo. 


\section{Categoria 01: Perfil Profissional}

Os profissionais obtiveram sua graduação entre os anos de 1984 e 2011, seis desses em universidades federais e dois em particulares, apenas um não possui pós-graduação, as especializações se dão em diferentes áreas, bem como: Gestão de Pessoas; Planejamento e Gestão Social; Política Social, Serviço Social e Processos de Supervisão de Estágio; Planejamento Social; Saúde Mental; Serviço Social, Direitos Sociais e Competências Profissionais; Gestão da Qualidade e Certificação; e Política e Pesquisa em Saúde Coletiva, dois assistentes sociais possuem ainda mestrado e residência em Serviço Social.

A maioria dos profissionais possui uma média de três anos de atividade no cargo de assistente social, com exceção de dois que trabalham nas empresas a dezesseis e vinte e cinco anos.

Os setores de atuação são os mais diversos, desde o próprio Serviço Social e Recursos Humanos, até Centro de Promoção da Saúde e Responsabilidade Social.

\section{Categoria 2: Processo de Formação}

Com relação ao processo de formação, a maioria dos pesquisados relatou que a formação oferecida pela graduação, no que diz respeito à atuação dos assistentes sociais nas organizações privadas, é satisfatória, visto que oferece subsídios para atuar em diferentes frentes de trabalho, já que é oferecida uma compreensão acerca da realidade social, com uma visão crítica, identificação da questão social e seus desdobramentos, assim como os diversos direitos da população. Sobre esse quesito o entrevistado E8 relou que: "A formação da faculdade de Serviço Social é generalista, com enfoque para a compreensão dos processos sociais que estabelece dentro da sociedade. (...) os conhecimentos que a gente tem nos possibilita uma inserção crítica, propositiva, ética dentro da empresa. É mais específico do trabalho do assistente social, apesar de que o trabalho do assistente social ele não difere muito, o que vai ser diferente são as relações institucionais, isso independente se você esta na saúde, empresa, no público, no privado; elas vão acontecer de formas diferentes".

O participante E6 mencionou ainda que: "Nossa formação é generalista, não tem foco em uma área determinada, entretanto a graduação nos dá às bases para o entendimento sobre a realidade social (...). Contudo se faz necessário uma busca por novos conhecimentos específicos da área em que a gente está atuando. Conhecer a dinâmica das políticas públicas com as quais a gente dialoga, conhecer as rotinas institucionais."

Ao longo das entrevistas pôde-se perceber uma grande importância dada por esses profissionais ao processo de formação, sempre buscando se especializar, seja por meio de cursos, palestras, congressos ou de programas de pós- graduação.

Com relação à oferta de cursos de treinamento e desenvolvimento para o Serviço Social, em sua grande maioria as empresas pesquisadas não possuem esse serviço, o que ocorre é a liberação para participação de palestras e congressos ou um subsídio para custeio de especializações. Contudo, três empresas oferecem cursos de treinamento com temas ligados ao trabalho desempenhado pelos assistentes sociais nas organizações, dentre eles voltados para a área de saúde, gerenciamento de pessoas e ligados a previdência.

\section{Categoria 3: Atuação do Assistente Social nas Empresas Privadas}

Em referência à visão que esses profissionais possuem sobre como tem se dado o desenvolvimento de seu trabalho nas empresas privadas, os entrevistados mencionaram a contradição inerente à profissão, ou seja, capital x trabalho, os interesses da empresa e os interesses do trabalhador. Logo, o profissional é chamado a atuar no sentido de mediador do 
conflito. Assim como foi relatado por E1 e por E6, respectivamente: "O papel é de moderador, mediando os interesses entre os trabalhadores e a empresa (...)". “(...) percebo a atuação junto aos trabalhadores no sentido de manter uma condição de saúde, uma condição laborativa, que atenda as necessidades da empresa. Garantindo condições para manter o trabalhador produzindo".

Amaral e Cesar (2009) corroboram desta ideia, uma vez que relatam que o assistente social é chamado a vir a intervir nas tensões inerentes às relações entre capital e trabalho.

De acordo com o ponto de vista dos participantes a atuação do profissional de Serviço Social nas empresas privadas é de suma importância, devido ao seu conhecimento técnico-operativo e teórico-metodológico que possibilitam um maior aproveitamento da força de trabalho, por meio da implementação de programas e projetos que beneficiam o trabalhador, fazendo com que esse obtenha um melhor desempenho na sua função o que consequentemente influenciará no aumento da produtividade da empresa e diminuição de gastos quanto a afastamentos, demissões e problemas relacionados ao uso de álcool e outras drogas. O que pode ser comprovado no relato de E6: "O assistente social hoje é muito importante porque ele dá conta das questões da vida privada do trabalhador, às vezes elementos que influenciam na produtividade dele na empresa, a gente dá conta de atuar em questões que não são específicas da área do trabalho. O que para a empresa é muito interessante. Para os trabalhadores o valor é maior ainda, porque a gente consegue fazer orientações e promover reflexões que nenhum outro setor conseguiria promover, na perspectiva dos direitos, da autonomia que ele tem, são coisas que o Serviço Social mobiliza e outros setores da empresa não tem nem a capacitação nem o compromisso político para fazer".

Os entrevistados partilham da mesma premissa que Borralho et al (2011), onde os autores declaram que a atuação do assistente social implica em interseções diretas na vida do trabalhador, por atuar junto aos valores, comportamentos, cultura e conhecimento.

Os assistentes sociais trazem como competências do profissional de Serviço Social nas empresas privadas o comprometimento com o projeto ético-político, a lei de regulamentação da profissão, o código de ética, conhecimento da rede sócio-assistencial, planejamento, gestão, destacaram ainda, capacidade investigativa, de leitura da realidade, ser propositivo, trabalho em equipe, criatividade, capacidade argumentativa, de articulação, visão crítica e postura estratégica. Conforme aludido por E4 e E8, nesta ordem: "Capacidade de negociação e articulação, visão crítica e postura estratégica." "Primeiro de tudo é ter conhecimento claro do projeto ético político, dos pilares que o fundamentam, a lei de regulamentação e o código de ética profissional. Conhecimento do trabalho que você desenvolve, conhecimento da rede sócio assistencial (...)".

Gomes et al (2010) mencionam que as atividade mais recorrentes nas empresas são: caráter pedagógico, a mediação entre trabalhador e a empresa, aplicação de treinamentos, integração dos trabalhadores e atendimento social.

Nesse sentido, segundo os entrevistados, as principais atividades desempenhadas pelo assistente social nas organizações privadas, seriam o atendimento ao público interno (trabalhador) e externo (familiares e comunidade). Sendo estas: atendimento a trabalhador afastado do trabalho; com comprometimento laborativo para a área de atuação; acompanhamento em processo de reabilitação profissional; abordagem social; visita domiciliar; análise sócio-econômica; atendimento aos familiares; ações de prevenção à saúde e uso de drogas; relacionamento com as lideranças comunitárias; gestão de benefícios; gestão de clima organizacional; gestão de projetos sociais; educação ambiental e programa de qualidade de vida no trabalho.

Já as demandas mais recorrentes são as relacionadas a: orientação de direitos previdenciários, direitos relativos à área da saúde, benefícios sócio-assistenciais, problemas 
com uso de álcool e outras drogas, violação de direitos, dispensação de equipamentos hospitalares e encaminhamento a rede sócio-assistencial.

Amaral e Cesar (2009) confirmam os relatos dos entrevistados onde aludem como demandas do assistente social mudança de hábitos, atitudes, comportamentos, de caráter educativo, referentes ao absenteísmo, alcoolismo, relacionados à vida privada do trabalhador e no que se refere aos conflitos familiares, dificuldades financeiras, doenças, tendo como foco a manutenção da força de trabalho.

Sobre esse assunto o entrevistado E3 relatou que as demandas mais recorrentes são: "(...) com relação a relacionamento interpessoal entre colegas de trabalho, saúde do trabalhador, acompanhamento de funcionários afastados, negociação/intermediação de questões do trabalhador com a empresa, análise para o processo de contratação e demissão de funcionários, planejamento anual da empresa".

A rede de serviços sócio-assistenciais mais utilizada pelos assistentes sociais entrevistados nas empresas privadas, segundo seus próprios relatos, são: Centro de Referência deAssistência Social (CRAS), Centro de Referência Especializado de Assistência Social (CREAS), hospitais, Unidade de Atenção Primária a Saúde (UAPS), previdência social, clínicas de reabilitação para dependentes químicos, serviços de psicologia, ouvidoria e superintendência de saúde, Centro de Atenção Psicosocial (CAPS), defesa civil e associação de moradores.

No que se refere à atribuição de funções que não são competência dos assistentes sociais, cinco entrevistados relataram não possuir nenhuma atividade que não seja competência desse profissional. Entretanto, três entrevistados referiram ter funções atribuídas ao Serviço Social que não são papel desse profissional, mas que, ao serem repassadas para o setor, o assistente social, por meio de sua escuta qualificada, acaba por desempenhar sua função por meio de alguma orientação relacionada a direitos ou até mesmo encaminhamento para a rede de serviços. Conforme, refere-se E5: "Às vezes ocorre, mas a partir dessas demandas, após a conversa, sempre tem alguma orientação a ser dada para os trabalhadores e seus familiares".

Gomes et al (2010) testificam o relato desse profissional, no sentido de que os autores tratam como a multifuncionalidade da atuação do assistente social, visto que exercem funções fora das competências e atribuições privativas desse profissional.

\section{Categoria 4: Facilitadores e Dificultadores do Processo de Trabalho do Assistente Social nas Empresas Privadas}

No que se refere à autonomia, os profissionais foram unânimes em dizer que é relativa, posto que em seu processo de trabalho tem liberdade para executa-lo, contudo devem reportar a gerência, a que o setor é submetido, sobre quaisquer decisões que por ventura venham a serem tomadas, como por exemplo a criação de algum programa ou projeto. Diversos relatos, como os a seguir demostram esse processo, E3, E5 e E8, respectivamente: "Autonomia relativa, submetido à gestão da empresa, subjugada aos interesses comerciais". "Para os procedimentos de atendimento temos autonomia, contudo sempre esbarramos no entendimento da gerência da importância em determinados processos". "Eu tenho autonomia com relação a como vou conduzir o meu atendimento, a questão é quando eu preciso de encaminhamento externo, principalmente quando eu vou vincular a justiça, por conta de processos que podem vir a onerar os custos da empresa".

Gomes et al (2010) corroboram essa percepção, afirmando que, em detrimento das limitações do processo de trabalho do assistente social nas empresas privadas, sua autonomia se faz relativa. Contudo, relatam que o profissional não pode se distanciar de seu projeto ético-político e de seu código de ética. Deve, portanto, recuar-se a cumprir orientações que não estejam de acordo com as posturas éticas recomendadas para sua profissão. 
Em sua maioria, os entrevistados disseram que o Serviço Social é reconhecido pela organização, no que diz respeito ao desenvolvimento de suas funções, contudo, ainda se esbarra na perspectiva conservadora, do profissional do cuidado. Conforme a própria fala dos assistentes sociais esse processo vem sofrendo alterações, visto que os profissionais tem demonstrado as empresas por qual motivo foram chamadas para trabalhar, qual a real atribuição do assistente social e principalmente, demonstrando através de resultados a sua real utilidade. E6 descreveu muito bem isso: "A organização ainda vê o Serviço Social como o profissional da ajuda, muitas vezes também acham que a gente tem atribuição de cuidar de todos os problemas que o trabalhador apresenta que não sejam específicos a atividade técnica, isso às vezes é um desafio, tentar mostrar que o nosso trabalho só tem resultados se ele for feito de uma maneira mais global, com a participação de outros profissionais. Entretanto, possui a clareza de que o assistente social tem uma perspectiva diferenciada para atuar junto aos trabalhadores."

Amaral e Cesar (2009) constatam que o Serviço Social possui reconhecimento por parte da gerência em sua facilidade de persuasão e inserção no cotidiano dos trabalhadores, reiterando o caráter pedagógico da profissão.

Em geral as ideias propostas pelos assistentes sociais são bem aceitas pelas organizações, todavia, devem atender interesses da organização para serem implementadas de fato, isto é, a empresa tem que ver benefício no que foi apresentado. O entrevistado E6 assim discorreu sobre esse fato: "É um trabalho bem reconhecido, somos constantemente requisitados. Para as ideias serem bem aceitas tem que ter uma argumentação muito forte sobre quais benefícios a empresa terá com a realização daquela atividade. Depende muito da chefia. Mas em geral o que se propõe é bem aceito".

Segundo os relatos colhidos, no que concerne aos facilitadores do processo de trabalho, entende-se pela liberdade na execução das tarefas; a importância atribuída ao clima organizacional, o que favorece as condições de trabalho do funcionário; abertura da própria gestão para propor ideias/soluções; condições éticas e técnicas que garantam o sigilo do trabalho e para o planejamento; o reconhecimento e a credibilidade do processo de trabalho. Quanto aos dificultadores, os entrevistados expuseram que são a falta de conhecimento da equipe acerca da profissão; o grande número de funcionários para, muita das vezes, um assistente social; ter que utilizar argumentações fortes para alcançar os objetivos propostos pelo setor; a burocracia nos processos ligados a benefícios e encaminhamentos e, a distância entre os setores em que ficam alocados os funcionários.

A seguir serão apresentadas as considerações finais acerca da percepção obtida pela autora sobre a pesquisa, a partir da análise de dados e consequentemente o fechamento do presente estudo.

\section{Considerações Finais}

A indagação sobre como tem se dado a atuação dos assistentes sociais nas empresas privadas norteou as discussões levantadas no desenvolvimento desse estudo. Acredita-se que o que foi levantado possibilitou uma melhor compreensão acerca do desenvolvimento das atividades desse profissional e seu processo de trabalho em geral.

O conceito de competência, destacado na segunda seção, possibilitou concluir que esse é um conjunto de conhecimentos, habilidades e atitudes desenvolvidas pelo trabalhador no desenvolvimento de sua função que agregam valor a organização.

Em seguida tratou-se da evolução histórica do Serviço Social nas empresas privadas, o que foi percebido é que a profissão desde sua origem nesse espaço sócio-ocupacional até a atualidade vem sofrendo diversas alterações em seu processo de trabalho seja na sua 
atuação ou nas demandas apresentadas, e até mesmo na criação de novos espaços e frentes de trabalho.

Já na quarta seção, foram analisadas as competências do assistente social na empresa privada, tomando como base a Lei de Regulamentação da Profissão e trabalhos desenvolvidos por diversos autores e na quinta seção foi realizada a descrição da metodologia utilizada.

Com relação aos resultados obtidos no campo a autora criou quatro categorias com o propósito de obter uma melhor análise do discurso, recorrendo à leitura dos textos buscando amostras discursivas recorrentes na fala dos entrevistados.

A primeira categoria esta relacionada ao perfil profissional e pode ser percebido que seis profissionais obtiveram sua graduação em universidades federais e dois em particulares, apenas um não possui pós-graduação, dois assistentes sociais possuem ainda mestrado e residência em Serviço Social. Os setores de atuação são os mais diversos, desde o próprio Serviço Social e Recursos Humanos, até Centro de Promoção da Saúde e Responsabilidade Social.

Em referência ao segundo quesito da categorização, alusivo ao processo de formação, a prevalência dos participantes foi que a formação oferecida pela graduação, no que se refere à atuação dos assistentes sociais nas organizações privadas, é satisfatória, dado que possibilita subsídios para atuar em diferentes áreas de atuação. Sendo uma formação generalista, já que é oferecido uma compreensão acerca da realidade social, com uma visão crítica da questão social e seus desdobramentos, e o conhecimento acerca dos direitos da população.

A partir da análise das entrevistas pôde-se perceber que os assistentes sociais atribuem grande relevância a formação continuada, ou seja, estão sempre buscando novos conhecimentos que agreguem valor ao seu processo de trabalho. Seja por meio de cursos, palestras, congressos ou através de programas de pós- graduação. Percebeu-se ainda, que em sua maioria as empresas não oferecem cursos de treinamento e desenvolvimento para os profissionais de Serviço Social, o que ocorre em algumas organizações é o custeio de programas de especialização e a dispensa dos profissionais para participação de palestras, congressos etc.

Partindo para o terceiro item da categorização, que é a atuação do assistente social nas empresas privadas, entendeu-se que os assistentes sociais tem uma visão sobre sua atuação nas empresas privadas voltada para a contradição entre capital $x$ trabalho, contradição esta inerente à profissão, uma vez que atuam na mediação de conflitos entre a empresa e o trabalhador, intervindo sempre na garantia dos direitos desse.

Os profissionais de Serviço Social entrevistados veem a sua atuação nas empresas privadas como de suma importância, pois é esse profissional que devido ao seu conhecimento técnico-operativo e teórico-metodológico e com sua visão do todo, obtém competências que outros profissionais não possuem e não tem um compromisso ético-político para trabalhar com determinadas questões relacionadas à relação entre empresa e trabalhador.

Os participantes trouxeram como competências do assistente social nas organizações privadas o comprometimento com o projeto ético-político, a lei de regulamentação da profissão, o código de ética, conhecimento da rede sócio-assistencial, ser um bom planejador, gestor, possuir capacidade investigativa, argumentativa, de leitura da realidade, de articulação, ser propositivo, criativo, saber trabalhar em equipe, ter uma visão crítica e uma postura estratégica.

As principais atividades desempenhadas pelos profissionais de Serviço Social entrevistados nas empresas são atendimento aos trabalhadores, seus familiares e a comunidade. Dentre as quais, destaca-se, atendimento ao trabalhador afastado do trabalho, com comprometimento laborativo para a área de atuação ou em processo de reabilitação profissional, abordagem social, visita domiciliar, análise sócio-econômica, atendimento aos familiares, ações de prevenção 
à saúde e uso de álcool e outras drogas, relacionamento com as lideranças comunitárias, gestão de benefícios, gestão de clima organizacional, gestão de projetos sociais, educação ambiental e programa de qualidade de vida no trabalho. Foi relatado pelos participantes que as demandas mais frequentes são as associadas à: orientação de direitos previdenciários, direitos relativos à área da saúde, benefícios sócio-assistenciais, problemas com uso de álcool e outras drogas, violação de direitos, dispensação de equipamentos hospitalares e encaminhamento a rede sócio-assistencial.

O quarto e último item da categorização são os facilitadores e difilcultadores do processo de trabalho do assistente social nas empresas privadas. À vista disso, com relação à autonomia, os profissionais entrevistados foram unânimes em dizer que a autonomia é relativa, dado que possuem autonomia em seu processo de trabalho, entretanto devem reportar a gerência a que o setor é submetido para realização de determinas programas e encaminhamentos. Relataram ainda que o Serviço Social é reconhecido pela organização, no tocante ao desenvolvimento de suas funções. Vale destacar a existência ainda da perspectiva conservadora, visto como profissional do cuidado, por parte da organização. Apesar disso tal processo vem sofrendo modificações, pois os profissionais têm demonstrado as empresas a importância da sua atuação e os resultados proporcionados a organização pelo desenvolvimento de seu trabalho.

Os facilitadores do processo de trabalho dos assistentes sociais, de acordo com os relatos dos profissionais são: a liberdade na execução das tarefas; a importância atribuída ao clima organizacional, o que favorece as condições de trabalho do funcionário; abertura da própria gestão para propor ideias/soluções; condições éticas e técnicas que garantam o sigilo do trabalho e para o planejamento; o reconhecimento e a credibilidade do processo de trabalho. Já os dificultadores são: a falta de conhecimento da equipe acerca da profissão; o grande número de funcionários para, muita das vezes, um assistente social; ter que utilizar argumentações fortes para alcançar os objetivos propostos pelo setor; a burocracia nos processos ligados a benefícios e encaminhamentos e, a distância entre os setores em que ficam alocados os funcionários.

Logo, o que pode-se perceber, foi que a atuação do assistente social nas empresas privadas ainda apresenta demandas e funções antigas, assim como inovou-se, a partir das novas requisições oriundas das mudanças no processo de trabalho em geral. A sua atuação vem se dando não somente na mediação entre o conflito do empregador e empregado, mas também com projetos mais amplos voltados para as praticas empresariais modernas de gestão do trabalho.

Tais modificações nesse espaço sócio-ocupacional têm aumentado à requisição do assistente social no quadro de funcionários das empresas e consequentemente, gerando mudanças em sua forma de atuação, exigindo uma constante formulação de estratégias no desenvolvimento de suas funções.

O profissional de Serviço Social, ao se inserir no espaço sócio-ocupacional das empresas privadas, deve possuir o compromisso de desenvolver ações que venham a contribuir para efetivação dos direitos dos trabalhadores, melhores condições de trabalho e uma ampliação na consciência política.

De acordo com a pesquisa realizada, pode-se dizer que o assistente social é um dos grandes mediadores de conflitos dentro do ambiente empresarial, visto que, possui competências que veem a contribuir no clima organizacional o que consequentemente acarretará numa mudança na produção dos trabalhadores. Isso pode ser alcançado por esse profissional possuir uma visão de mundo a longo prazo; compreensão e vivência de valores holísticos; argumentação para negociar e criar projetos; bem como, atuar em prol dos direitos dos funcionários e em paralelo ao desenvolvimento da organização.

A pesquisa possibilitou perceber que a atuação do assistente social nas empresas 
privadas é marcada por diversos antagonismos, mas que ainda assim é possível direcionar seu trabalho para os interesses dos trabalhadores em paralelo aos interesses de lucratividade do capital, por meio de estratégias que se articulem ao projeto ético-político do Serviço Social. Nesse sentido, o assistente social tem que ter um compromisso com o projeto ético-político da profissão, com a equidade e a justiça social e em defesa dos direitos do trabalhador.

Em suma, é o assistente social é o profissional que tem a função de promover reflexões que gerem consciência política aos trabalhadores e a população, questionando a ordem social estabelecida.

O presente trabalho não pretende esgotar o tema, mas sim sugerir a continuidade do estudo sobre a atuação do assistente social nas empresas privadas, visto que a pesquisa foi realizada com um número restrito de entrevistados.

\section{REFERÊNCIAS BIBLIOGRÁFICAS}

AMARAL, A. S.; CESAR, M. J. O trabalho do assistente social nas empresas capitalistas. In: CFESS IABEPSS. (Org.). Serviço Social: Direitos Sociais e Competências Profissionais. 1ed. Brasília: CEFESS/ABEPSS, 2009, v. 1.

BARDIN, L. Análise de conteúdo. Lisboa: Edições 70, 2008.

BRANDÃO, H. P.; BABRY, C. P. Gestão por competência: métodos e técnicas para mapeamento de competências. Brasília: Revista do Serviço Público Brasília, p. 179-194, Abr./ Jun. 2005.

BRANDÃO, H. P.; GUIMARÃES, T. A. Gestão de competências e gestão de desempenho: tecnologias distintas ou instrumentos de um mesmo constructo? Revista de Administração de Empresas, São Paulo, v.41, n. 1, p. 8 - 15, Jan./Mar. 2001.

BRASIL. Regulamentação da Profissão. Lei n8.662 de 7 de junho de 1993.

BORRALHO, A. C. T.; SOUSA, I. P.; OLIVEIRA, F. A. O assistente social atuando na área de recursos humanos para a melhoria do clima organizacional. Revista Científica do ITPAC, Araguaína, v. 4, Pub. 3, Out. 2011.

CARBONE, P. P.; BRANDÃO, H. P.; LEITE, J. B. D.; VILHENA, R. M. de P. Gestão por competências e gestão do conhecimento. 2a ed. Rio de Janeiro: Editora FGV, p. 41-79, 2006.

CESAR, M. J. Serviço social e reestruturação industrial: requisições, competências e condições de trabalho profissional. In: MOTA, A. E. (org.) A nova fabrica de consensos. São Paulo: Cortez, 2010. p. 115 - 148.

DOURADO. E. O. Reestruturação nos bancos e a ação do Serviço Social. In: MOTA, A. E. (org.) A nova fabrica de consensos. São Paulo: Cortez, 2010. p. 149 - 165.

DUTRA, J. S. Gestão de pessoas com base em competências. In: DUTRA, J. S. (org.) Gestão por competência. São Paulo: Ed. Gente, 2001.

FERREIRA, V. C. P.; LANA, M. S. Gestão por competência: impactos na gestão de pessoas. Juiz de Fora: Estação Cientifica Online, n. 04, Abr./Mai. 2007.

FLEURY, A. C. C.; FLEURY, M. T. L. Construindo o conceito de competência. Curitiba: Revista de Administração Contemporânea, 2001, vol. 5.

GOMES, A. M.; MENDONÇA, A. C.; QUEIROZ, G. L. D.; SILVA, H. V.; LIMA, L. A.; MELO, L. C.; ROCHA, M. R. S. O espaço sócio-ocupacional dos assistentes sociais na área de empresas do município de Natal. Natal: Interface, jul./dez. 2010 - vol. 7 - n .2.

IAMAMOTO, M. V.; CARVALHO, R. Relações sociais e Serviço Social no Brasil: esboço de interpretação histórico-metodológica. 6 ed. São Paulo: Cortez, 1982. 
LEME, R. Aplicação prática de gestão de pessoas por competência. Rio de Janeiro: Qualitymark, 2005.

MOTA, A. E. O feitiço da ajuda: as determinações de serviço social na empresa. São Paulo, Cortez, 1985.

SILVA, M. de O. Gestão de pessoas através do sistema de competências: estratégia, desempenho e remuneração - fundamentos e aplicação. Rio de Janeiro: Qualitymark, 2005, p. 5-15, p. 86-89.

TADEUCCI, M. de S. R.; BELFORT, R. M.; SANTOS, E. di F. M. da S. Gestão por competência: um novo modelo de gerenciamento. Imperatriz: Revista UNI, 2012, Jan./Julh., ano 2, n. 2, p. 39-53.

VERGARA, S. C. Métodos de coleta de dados no campo. São Paulo: Atlas, 2009.

Atlas, 2011.

, S. C. Projetos e relatórios de pesquisa em administração. 13 ed. São Paulo: 